\title{
Factors influencing the decision that women make on their mode of delivery: the Health Belief Model
}

\author{
Alice Yuen Loke ${ }^{*}$, Louise Davies and Sau-fun Li
}

\begin{abstract}
Background: Childbirth is regarded as an important life event for women, and growing numbers of them are making the choice to give birth by Caesarean Delivery. The aim of this study was to identify the factors influencing the decision that women make on their mode of delivery, underpinned by the Health Belief Model.

Methods: This was a cross-sectional study. Hong Kong Chinese women aged 18-45, who were pregnant or had given birth within the last three years were recruited. The participants were asked to complete a structured self-administered questionnaire consisting of 62 questions.

Results: A total of 319 women were recruited, of whom 73 (22.9\%) preferred to have a cesarean section delivery (CD). The results showed that women preferred CD because they were concerned about being pregnant at an advanced age, were worried about labor pain and perineum tearing, wanted to have a better plan for maternity leave, had chosen an auspicious date to deliver, and perceived that CD is a more convenience way to deliver. The perceived benefits and severity of a vaginal birth (VB), and the perceived benefits, severity, and cues to action of $C D$, affected the decision to undergo either a VB or CD.

Conclusions: The data indicated that the constructs of the Health Belief Model - perceived benefits, perceived severity, and cues to action - affect the decision that women make on their mode of delivery. This research indicates that there is value in designing educational programs for pregnant women to educate them on the benefits, risks, and severity of the two different modes of birth based on the constructs of HBM. This will enable women to be active participants in choosing the mode of birth that they believe is right for them.
\end{abstract}

Keywords: Mode of delivery decisions, Cesarean section, Vaginal birth, Health Belief Model

\section{Background}

Historically, the natural process of Vaginal Birth (VB) has been viewed as the unquestioned mode of birth, whereas Caesarean Section Delivery (CD), which involves an operative incision, has been perceived as a risky procedure designed for women with medical indications [57]. With advances in reproductive technology, an increase in the number of CDs has been observed in recent years [9]. There has also been a shift in the attitudes, so that it is no longer unusual for couples to request a CD [30]. "Caesarean Delivery on Maternal Request" (CDMR) refers to a primary CD performed

\footnotetext{
* Correspondence: hsaloke@polyu.edu.hk

School of Nursing, The Hong Kong Polytechnic University, 11 Yuk Choi Rd, Hung Hom, Hong Kong
}

prior to labor in the absence of medical indications, where women are choosing for themselves their preferred mode of birth [57].

Childbirth is regarded as an important life event for women, and growing numbers of them are making the choice to give birth by $\mathrm{CD}$. The escalating CDMR rate is associated with the perception of women that $\mathrm{CD}$ is the safer mode of birth [51]. However, the evidence to support this belief is limited.

Rates of CDMR seems to be increasing worldwide, more so in some countries than others. According to a report by the National Institute of Health [38], approximately $4-18 \%$ of all babies in the United States were born by CDMR in 2004. Overall, CDs in the United States have increased from $22.9-32.8 \%$ between 2000 
and 2010 [31]. In 2011, it was reported that $8 \%$ of the increase in CDs at a major hospital in the United States was attributable to CDMR [3].

Much higher rates of CDs are observed in Asian countries. In the urban regions of China, a CD rate of $54.1 \%$ was reported in 2008 [54] followed by Taiwan at 35.2\% in 2007 [8]. Between the years 1998 to 2008 in China, the rate of CDs in rural regions rose from 3.6 to $23.6 \%$, and that for urban regions rose from 19.9 to $54.1 \%$ [54]. There is evidence of an increase in the CDMR rate from $0.8 \%$ in 1994 to $20 \%$ in 2006 [24]. According to a territory-wide obstetric audit in Hong Kong, elective CDs for non-medical indications increased from $5.5 \%$ of all CDs in 1994 to $16.7 \%$ in 2004 [19]. A more complete picture of the number of babies being delivered by CDMR will help to determine whether rates of CDs are indeed increasing.

Factors influencing maternal preference of mode of birth There are various factors influencing a woman's choice of mode of birth. Demographic factors and an individual's expectation of childbirth have a bearing on her decision-making process. Others are previous birth experience, potential complications arising from the mode of birth, and concerns over the health and safety of mother and baby [41].

\section{Application of the health belief model on the maternal choice of mode of birth}

In the present study, the Health Belief Model (HBM) was adopted as a conceptual framework, to provide a sound theoretical basis for understanding the factors that influence women's childbirth decisions. The HBM can specify the relationship between health-related beliefs/factors and maternal behaviors, which can help in predicting the possibility of a woman choosing a particular mode of birth. Using this model, mode of birth and maternal choice and its determining factors can be explored within the five domains of the HBM, namely: perceived susceptibility, perceived severity, perceived benefits, perceived barriers, and cues to action [23].

\section{Perceived susceptibility}

Perceived susceptibility is a person's belief in his/her vulnerability to some medical condition. The more that a person believes he/she is at great risk, the more likely that person is to adopt a particular health-related behavior to minimize such risk [23]. For instance, a negative experience in a previous birth could affect a woman's preference for a particular mode of birth in subsequent births, due to the belief that the negative experience could occur again [40].

\section{Perceived severity}

Perceived severity is defined as one's belief in the intensity of the medical condition and its undesirable outcomes [23]. If it is believed that there are very serious or intolerable complications associated with a specific mode of birth, women are more likely to express a preference for an alternative method of delivery, so as to reduce their risk.

For both $\mathrm{VB}$ and $\mathrm{CD}$, the most severe complications are maternal and neonatal mortality [47]. A global survey by the World Health Organization between 2004 and 2008 reported the risks of maternal mortality and morbidity in CD without medical indications [28]. The risks due to $C D$ were three times greater than those for $\mathrm{VB}$, including in the areas of maternal mortality, admission to an intensive care unit, the need for a blood transfusion, and the need to carry out a hysterectomy or internal iliac artery ligation. It was noted that $C D$ can have several negative consequences on maternal health, including adverse outcomes related to anesthesia, adhesion formation, and uterine rupture [47]. Neonatal respiratory depression secondary to maternal anesthesia has also been identified as a risk associated with CD [10].

However, VB is not without risk. Maternal complications associated with VB include pelvic organ prolapse, prolonged labor, and perineal trauma [1, 41]. For the neonate, there is also an increased risk of contracting infections such as Hepatitis C, HIV, and HPV during vaginal birth from maternal to neonate transmission [47].

\section{Perceived benefits}

Perceived benefits are defined as one's belief that outcomes can be positively affected by engaging in a particular health behavior [23]. The advantages of maternal and fetal health and a sense or anticipating fulfillment and satisfaction of sociocultural beliefs have been identified as important factors in maternal decision making.

When considering the perceived benefits for the health of childbearing women, it has been noted that in a number of countries women associate VB with a greater number of benefits than CD. Women in Singapore (91.5\%), Turkey (89\%), and the USA (42\%) believed that VB offers a faster recovery, earlier discharge, and the absence of a CD scar [7, 10, 27, 42].

When focusing on neonatal health, nearly $60 \%$ of women believed that VB is safer for the baby [10]. Women also reported that VB enables earlier bonding with their baby and early initiation of breastfeeding.

In comparison, a fear of labor (50\%) and repetitive vaginal examinations (23\%) were underlying reasons why women showed a preference for CD [10]. This was supported by women identifying tocophobia (an intense fear of labor contractions), prolonged labor, fetal distress, and the perineal trauma associated with $\mathrm{VB}$ as reasons for why they planned to have a $\mathrm{CD}[5,32,40,52]$. 
Women also took into consideration the advantages of $\mathrm{CD}$ in maintaining genital appearance (24\%), facilitating tubal ligation (20.6\%), and minimizing sexual dissatisfaction $(0.8 \%)$ following delivery $[5,10]$.

From another perspective, women also perceived CD as more convenient, allowing them to better plan their maternity leave. It is also of significance that within the Chinese culture, some women strongly believe that an auspicious time of birth is vital to a person's lifelong fate and destiny [21]. It has been noted that the birth rate in the year of the dragon in the Chinese zodiac, a particularly auspicious year, rises [55].

\section{Perceived barriers}

Perceived Barriers refers to an individual's perception of the difficulties stopping them from following a specific health-related behavior [23]. The desire to choose VB is hindered by existing medical contraindications. There are some medical contraindications of VB for mothers, including pelvic disproportion, pre-eclampsia, severe cardiovascular disease, diabetes mellitus, active genital herpes, HIV infection, and multiple pregnancies [4, 29, 48]. On the other hand, the medical contraindications for babies include fetal malpresentation, fetal malformation, cord prolapse, and macrosomia $[39,49]$.

In Hong Kong, CDMR is only available in the private sector, as public hospitals will not permit this practice. The cost of a CDMR in the private sector ranges from $\$ 23,000$ to $\$ 66,800$ (all figures are quoted in Hong Kong dollars) or even higher, which is far more expensive than a VB $[18,20]$. Given that the median monthly household income in Hong Kong was about \$18,000 in 2010 [22], this implies that women of lower financial status cannot afford the CDMR plan in the private sector. Both public hospital policy and low financial status could act as barriers to choosing a CD. Studies have shown that insurance coverage is a vital element in the maternal choice of delivery, with studies conducted in Australia and Chile indicating that insurance coverage encourages women to attend private hospitals and hence encourages CDMR [12, 37].

\section{Cues to action}

Cues to action refer to the factors that help individual make health-related decisions [23]. Advice from relatives, friends, health care professionals, as well as an awareness of the rights of women are crucial factors guiding the maternal decision on delivery method.

Women's beliefs and attitudes towards a particular mode of delivery are strongly influenced by the stories and advice that they hear from relatives and friends $[5,11]$. Women were driven to an alternative mode of delivery after hearing negative stories about a particular mode increasing concern that they might have the same experience when they gave birth $[33,46]$. In addition, the pregnant woman might also worry if there is a family history of poor obstetric outcomes [43]. Advice from health care professionals such as midwives and doctors very much influences a woman's understanding of a particular delivery mode and her preference for it [13].

Other than advice from others, some women perceived that they should have their own right to decide the mode of delivery [25]. This is a major reason why CDMR rates are increasing worldwide [41].

\section{Significance of the study}

The issue of maternal preference for a particular mode of birth is complex. The aim of this study is to examine the perceptions of Hong Kong women towards CD and $\mathrm{VB}$, as well as their priorities when they are considering their mode of birth. With insight into women's attitudes and preferences on mode of birth, midwives and obstetricians can better support women by providing appropriate information during pregnancy, enabling them to make an informed choice and take an active part in the decision-making process.

\section{Methods}

\section{Study design}

This was a descriptive cross-sectional study. A structured self-administered questionnaire was used to collect information from Hong Kong women of childbearing age on their preference for mode of birth and the factors that influenced this preference, guided by the five constructs of HBM.

\section{Study setting and sampling}

The target population of this study was married Hong Kong women aged 18-45. The criteria for inclusion in this study were women who are (1) permanent Hong Kong residents and able to read and write Chinese, and (2) pregnant or had given birth within the past three years. Women who had medical indications for $\mathrm{CD}$ were excluded.

A convenient sampling strategy was adopted to recruit the potential participants, on the basis of their availability and willingness to participate. Women were approached as they were entering or leaving public hospitals under the jurisdiction of the Hospital Authority or from Maternal and Child Health Centers across various districts of Hong Kong, including those located in the eastern part of Hong Kong, Kowloon Center, Kowloon West, and the New Territories. Self-administered questionnaires were distributed to those who agreed to fill them out. The questionnaire took an average of approximately $10-15$ mins to complete.

All potential participants were invited to take part in the study in August and September of 2013. The sample 
size was determined based on the general rule that $5-10$ subjects need to be recruited for each item in a questionnaire [17]. As the questionnaire contains 47 items (excluding demographic questions), a total of 235-470 subjects needed to be recruited.

\section{Questionnaire development}

A questionnaire was developed specifically for this study based on the studies of Chong and Mongelli [7], Pang et al. [40], Buyukbayrak et al. [5], and Dursun et al. [10], which identified a maternal preference for $\mathrm{VB}$ or $\mathrm{CD}$.

The questionnaire is made up of four parts. Part A collects the socio-demographics data of the participants. Part B was designed to collect information on a woman's preference on mode of birth (without financial and medical considerations), sources of information, and the factors influencing their preference.

Parts $\mathrm{C}$ and $\mathrm{D}$ of the questionnaire contain different statements about the different perceptions relating to $\mathrm{VB}$ and $\mathrm{CD}$ correspondently based on the five constructs of HBM: perceived susceptibility, perceived benefits, perceived severity, perceived barriers, and cues to action. Previous studies discussing the influencing factors and attitudes toward $\mathrm{VB}$ and $\mathrm{CD}$ formed the basis for the questionnaire items in these two parts $[5,7]$. The women were asked to indicate their level of agreement towards the statements using a four-point Likert Scale (strongly disagree, disagree, agree, and strongly agree). This evenpoint scale requires the respondent to give either a positive or negative response, as no option for a neutral response is provided.

There were 21 items in Part $\mathrm{C}$, measuring the perceived susceptibility ( 2 items), perceived benefits (10 items), perceived severity ( 5 items), perceived barriers (1 item), and cues to action (3 items). There were 26 items in Part D, measuring the perceived susceptibility (2 items), perceived benefits (15 items), perceived severity (3 items), perceived barriers ( 2 items), and cues to action (4 items). For the calculation of mean scores, "strongly agree" was assigned a score of 2 and "agree" a score of 1 , whereas no score was accorded to the scales "disagree" or "strongly disagree". A higher score signifies a stronger perception of a specific construct.

\section{Validity and reliability}

A panel of experts that included an obstetrician, a midwife, and an obstetric nurse was invited to validate the questionnaire. Most of the questionnaire items were evaluated by the three experts as appropriate and relevant to the study, with the Content Validity Index equal to 0.94 . Minor amendments were made to the wording and order of the questionnaire to achieve a more logical layout. A pilot study was then conducted before the commencement of the study in August 2013 among 30 women to test the comprehensibility of the items and to establish the reliability of the questionnaire. Further amendments were made to unfamiliar phrases that required clarification from the women in the pilot study. The overall Cronbach's alpha of the pilot study was calculated to be 0.896 , indicating that the instrument has a high level of internal consistency.

\section{Ethical considerations}

Ethical approval was obtained from the Human Subjects Ethics sub-committee of the Hong Kong Polytechnic University prior to the commencement of the study. All eligible women were recruited on a voluntary basis. Potential participants were provided with a written information sheet stating the purpose of the study and details regarding adherence to the Privacy Ordinance, supplemented with an explanation if needed, before their written consent was obtained. The returned questionnaires were anonymous and could not be identified by the researchers. Only the authorized researchers could access data for analysis.

\section{Statistical analysis}

The data that were obtained were entered and analyzed using IBM Statistical Package for Social Sciences (SPSS Version 19.0, USA). Descriptive statistics and a Chisquare test were used to identify and compare the demographic information, influencing factors, and the five constructs of the HBM between two preference groups. An unpaired $t$-test was used to determine whether there were any statistically significance differences regarding perceived benefits, severity barriers, and cues to action between women who prefer VB and CD. Finally, logistic regression was used to determine whether maternal characteristics and scores derived from constructs of HBM are predictors of maternal preference on mode of delivery. The significance level $(\alpha)$ was set at 0.05 .

\section{Results}

During the data collection period 340 Hong Kong women who fulfilled the criteria for inclusion were invited to participate in the study. A total of 326 women consented to take part in the study, for a response rate of $95.9 \%$. Of these, 7 returned questionnaires were incomplete and excluded, leaving 319 valid questionnaires for analysis.

\section{Characteristic of the study participants}

The questionnaires from the 319 respondents were analyzed in this report. The demographics of the women who participated are shown in Table 1 . The majority of the women were between $26-35$ years of age (71.5\%), with $18 \%$ in the age group of 36-45. Two-thirds were pregnant $(66.7 \%)$ and one-third (33.3\%) of the women 
Table 1 Demographics of women of childbearing age in Hong Kong: comparison between women who prefer a vaginal birth (VB) and a cesarean delivery (CD) $(n=319)$

\begin{tabular}{|c|c|c|c|c|}
\hline & $\begin{array}{l}\text { Total } \\
(\mathrm{n}=319) \\
\mathrm{n}(\%)\end{array}$ & $\begin{array}{l}\text { Prefer VB } \\
(\mathrm{n}=246) \\
\mathrm{n}(\%)\end{array}$ & $\begin{array}{l}\text { Prefer CD } \\
(\mathrm{n}=73) \\
\mathrm{n}(\%)\end{array}$ & P-value \\
\hline Age group & & & & $0.008^{* *}$ \\
\hline $18-25$ & $33(10.3)$ & $25(10.2)$ & $8(11.0)$ & \\
\hline $26-35$ & $228(71.5)$ & $185(75.2)$ & $43(58.9)$ & \\
\hline $36-45$ & $58(18.2)$ & $36(14.6)$ & $22(30.1)$ & \\
\hline Place of birth & & & & 0.488 \\
\hline Hong Kong & $252(79.0)$ & $198(80.5)$ & $54(74.0)$ & \\
\hline Outside Hong Kong (China and Asia) & $67(21.0)$ & $48(19.5)$ & $19(26.0)$ & \\
\hline Place of residence & & & & 0.470 \\
\hline New Territories & $166(52.0)$ & $130(52.8)$ & $36(49.3)$ & \\
\hline Kowloon & $125(39.2)$ & $97(39.4)$ & $28(38.4)$ & \\
\hline Hong Kong Island & $28(8.8)$ & $19(7.7)$ & $9(12.3)$ & \\
\hline Educational level & & & & $0.016^{*}$ \\
\hline Tertiary or above & $185(58.0)$ & $153(62.2)$ & $32(43.8)$ & \\
\hline Secondary school & $133(41.7)$ & $92(37.4)$ & $41(56.2)$ & \\
\hline Primary school & $1(0.3)$ & $1(0.4)$ & $0(0.0)$ & \\
\hline Employment status & & & & 0.446 \\
\hline Homemaker & $88(27.6)$ & $66(26.8)$ & $22(30.1)$ & \\
\hline Full time employment & $209(65.5)$ & $165(67.1)$ & $44(60.3)$ & \\
\hline Part-time employment & $22(6.9)$ & $15(6.1)$ & 7 (9.6) & \\
\hline Women's occupation & & & & $0.016^{*}$ \\
\hline Non-health related & $293(91.8)$ & $221(89.8)$ & 72 (98.6) & \\
\hline Health related: & $26(8.2)$ & $25(10.2)$ & $1(1.4)$ & \\
\hline Physician & & $1(0.4)$ & $0(0.0)$ & \\
\hline Nurse & & $15(6.1)$ & $1(1.4)$ & \\
\hline Allied health (PT/OT) & & $9(3.6)$ & $0(0.0)$ & \\
\hline Monthly household income & & & & 0.240 \\
\hline HK\$ 0-10,000 & $17(5.3)$ & $11(4.5)$ & $6(8.2)$ & \\
\hline HK\$ 10,001-20,000 & $79(24.8)$ & $59(24)$ & $20(27.4)$ & \\
\hline HK\$ 20,001-30,000 & $78(24.5)$ & $57(23.2)$ & $21(28.8)$ & \\
\hline HK\$ 30,001-40,000 & $48(15.0)$ & $37(15)$ & $11(15.1)$ & \\
\hline Over HK\$ 40,000 & $97(30.4)$ & $82(33.3)$ & $15(20.5)$ & \\
\hline \multicolumn{5}{|l|}{ Sources of information on modes of delivery: } \\
\hline Obstetrician & $196(61.4)$ & $150(61.0)$ & $46(63.0)$ & 0.753 \\
\hline Nurses & $71(22.3)$ & $56(22.8)$ & $15(20.5)$ & 0.689 \\
\hline Relatives & $105(32.9)$ & $84(34.1)$ & $21(28.8)$ & 0.390 \\
\hline Friends & $86(27.0)$ & $66(26.8)$ & $20(27.4)$ & 0.923 \\
\hline Previous birth experience & $82(25.7)$ & $65(26.4)$ & $17(23.3)$ & 0.590 \\
\hline Internet / books & $81(25.4)$ & $72(29.2)$ & $9(12.3)$ & $0.03^{*}$ \\
\hline
\end{tabular}

${ }^{*}=\mathrm{P}<0.05,{ }^{* *}=\mathrm{P}<0.01$ 
had given birth within the past three years. The majority (79\%) were born in Hong Kong. Over half $(52 \%)$ were recruited from the New Territories. Well over half had attained a tertiary level education (58\%) and held full-time employment (65.5\%). Only $8.2 \%$ were health professionals. Nearly one third (30.4\%) had a monthly household income of more than HK\$40,000, and about half had a monthly income of HK\$10,001-30,000.

Overall, without financial and medical considerations, 246 out of the 319 women (77.1\%) indicated a preference for $\mathrm{VB}$, while the remaining 73 women $(22.9 \%)$ preferred $\mathrm{CD}$. The demographic characteristics of the respondents were further compared according to the maternal preference of mode of birth using Chisquare tests (Table 2). Those who preferred CD, when compared with those who preferred VB, were more likely to be in the advanced maternal age group of over 36 years old ( $30.1 \%$ vs. $14.6 \%)$, less likely to have received a tertiary level education ( $43.8 \%$ vs. $62.2 \%)$, and more likely to be in a non-health related profession (98.6\% vs. $89.8 \%$ ). There were statistically significant differences between the two groups of women in terms of age $(\mathrm{p}=$ $0.008)$, level of education $(\mathrm{p}=0.016)$, and occupation $(\mathrm{p}=$ 0.016 ).

Over half of the women (61.4\%) reported that they had been provided with information on the different modes of delivery by relatives (32.9\%) and friends (27\%), and to a lesser extent from nurses $(22.3 \%)$.

\section{Factors influencing mode of birth}

Women were asked to indicate, if given a free choice on mode of birth without financial and medical considerations, all of the factors that they would consider when making a decision on $\mathrm{VB}$ or $\mathrm{CD}$. Table 2 shows the factors that these women took into consideration Table 2.

Table 2 Considerations when making the decision on mode of delivery: Comparison between women who prefer a vaginal birth (VB) and a cesarean delivery (CD) $(n=319)$

$\begin{array}{lll}\text { Prefer VB } & \text { Prefer CD } & \text { P-value } \\ (\mathrm{n}=246) & (\mathrm{n}=73) & \\ \mathrm{n}(\%) & \mathrm{n}(\%) & \end{array}$

Baby's factors

$\begin{array}{llll}\text { Health of the newborn } & 209(85.0) & 39(53.4) & <0.001^{* * *} \\ \text { Birth trauma to the newborn } & 52(21.1) & 24(32.9) & 0.039^{*} \\ \text { Respiratory trauma to the newborn } & 20(8.1) & 10(33.7) & 0.152 \\ \text { Newborn's birth presentation } & 24(9.8) & 13(17.9) & 0.059 \\ \text { Large baby } & 23(9.3) & 5(21.9) & 0.004^{* *} \\ \text { Twins/triplets } & 5(2.0) & 5(6.8) & 0.038^{*}\end{array}$

Maternal factors

Maternal health

$180(73.2)$

$17(6.9)$

Labor pain

$47(19.1)$

Unsightly abdominal scars

$63(25.6)$

Worry about tearing of the perineum

$18(7.3)$

$6(2.4)$

Possible anal/urinary incontinence due to VD

$1(0.4)$

Social factors

Natural way of delivery

$122(49.6)$

$7(2.8)$

8 (3.3)

8 (3.3)

4 (1.6)

$11(4.5)$

Medical insurance coverage

$0(0.0)$

Women should have the right to choose

14 (5.7)
33(45.2)

$22(30.1)$

58 (79.5)

5 (6.8)

$19(26.0)$

19 (26.0)

12 (16.4)

$<0.001^{* * *}$

$<0.001^{* * *}$

$<0.001^{* * *}$

$0.0010^{* *}$

$<0.001^{* * *}$

$<0.001^{* * *}$

$<0.001^{* * *}$

$<0.001^{* * *}$

$<0.001^{* * *}$

$<0.001^{* * *}$

$<0.001^{* * *}$

$<0.001^{* * *}$

0.511

$<0.001^{* * *}$

$<0.005^{* *}$ 
The most commonly cited reasons for preferring VB were "concern for health of the newborn" (85\%), followed by "concern for maternal health" (73.2\%), and "being a natural way of delivery" (49.6\%). The main reasons for preferring CD were "avoidance of labor pain" (79.5\%), "concern for the health of the newborn" (53.4\%), and "concern for maternal health" (45.2\%). Statistically significant differences between the two groups of women preferring $\mathrm{VB}$ or $\mathrm{CD}$ were demonstrated for the most popular influencing factors $(\mathrm{P}<0.001)$.

\section{Constructs of the health belief model}

The women's perceptions of VB and CD were assessed based on the five constructs of HBM: perceived susceptibility, benefit, severity, barriers, and cues to action. A comparison was then made between women who preferred the two different modes of delivery.

Table 3 shows the women's perceptions of VB according to the five constructs of HBM, and the comparison between the two groups of women. Among women who expressed a preference for VB, only a small number considered themselves susceptible to common complications such as "painful labor" $(\mathrm{n}=15)$ and postpartum hemorrhage $(n=4)$ due to VB. Women who expressed a preference for $\mathrm{VB}$ in comparison with those who preferred $C D$ were more likely to perceive the benefits of VB. The top three benefits of VB were deemed to be: "a normal or natural process" (100 vs. $75.4 \%$ ), "allows early breastfeeding" (94.7\% vs. 76.7\%), and "faster recovery" (98.4\% vs. 64.4\%). Statistically significant differences were found for all three items, with $\mathrm{p}=<0.001$. Women

Table 3 Constructs of HBM relating to women's perceptions of vaginal birth (VB): Comparison between women who prefer a vaginal birth (VB) and a cesarean delivery (CD) $(n=319)$

\begin{tabular}{|c|c|c|c|}
\hline Women's perception of vaginal birth (VB) & $\begin{array}{l}\text { Prefer VB } \\
(\mathrm{n}=246) \\
\mathrm{n}(\%)\end{array}$ & $\begin{array}{l}\text { Prefer CD } \\
(\mathrm{n}=73) \\
\mathrm{n}(\%)\end{array}$ & P-value \\
\hline \multicolumn{4}{|l|}{ Perceived susceptibility } \\
\hline Painful labor process & $10(0.04)$ & $5(0.07)$ & 0.455 \\
\hline Postpartum hemorrhage & $1(0.004)$ & $3(0.04)$ & $0.034^{*}$ \\
\hline \multicolumn{4}{|l|}{ Perceived benefits } \\
\hline VB is a normal/natural process & $246(100.0)$ & $55(75.4)$ & $<0.001^{* * *}$ \\
\hline Allows early contact with newborn after delivery & $230(93.5)$ & $48(65.8)$ & $<0.001^{* * *}$ \\
\hline Allows early breastfeeding & $233(94.7)$ & $56(76.7)$ & $<0.001^{* * *}$ \\
\hline Shorter hospital stay & $228(92.7)$ & $45(61.6)$ & $<0.001^{* * *}$ \\
\hline Faster recovery after delivery & $242(98.4)$ & $47(64.4)$ & $<0.001^{* * *}$ \\
\hline No unnecessary surgical wound pain & $225(91.4)$ & $41(56.2)$ & $<0.001^{* * *}$ \\
\hline No need for an operation and anesthesia & $231(93.9)$ & $48(65.7)$ & $<0.001^{* * *}$ \\
\hline The fate of my baby is determined by nature & $193(78.4)$ & $28(38.4)$ & $<0.001^{* * *}$ \\
\hline Less costly & $209(84.9)$ & $55(75.3)$ & 0.056 \\
\hline Covered by insurance/hospital authority & $122(49.6)$ & $29(39.7)$ & 0.138 \\
\hline \multicolumn{4}{|l|}{ Perceived severity } \\
\hline Risk of fetal injuries when the baby goes through the vaginal canal & $97(39.4)$ & $66(90.4)$ & $<0.001^{* * *}$ \\
\hline Risk of mother-to-child transmission of infectious agents during vaginal birth & $131(53.2)$ & $63(86.3)$ & $<0.001^{* * *}$ \\
\hline Worry about perineal tears due to vaginal birth & $108(43.9)$ & $64(87.7)$ & $<0.001^{* * *}$ \\
\hline Afraid of damage to the pelvic floor due to vaginal birth & $84(34.2)$ & $55(75.4)$ & $<0.001^{* * *}$ \\
\hline Concern over having urinary/anal incontinence if a vaginal delivery is performed & $90(36.6)$ & $52(71.2)$ & $<0.001^{* * *}$ \\
\hline \multicolumn{4}{|l|}{ Perceived barriers } \\
\hline Carry insurance coverage for CD in private hospitals & $76(30.9)$ & $26(35.6)$ & 0.447 \\
\hline \multicolumn{4}{|l|}{ Cues to action } \\
\hline Healthcare professionals advise VB & $203(82.6)$ & $52(71.2)$ & $0.034^{*}$ \\
\hline Relatives/friends advise VB & $206(83.7)$ & $45(61.6)$ & $<0.001^{* * *}$ \\
\hline Have heard negative stories from relatives/friends about their cesarean delivery & $78(31.7)$ & $24(32.8)$ & 0.851 \\
\hline
\end{tabular}

${ }^{*}=\mathrm{P}<0.05,{ }^{* * *}=\mathrm{P}<0.001$ 
who preferred VB were significantly less worried about the perceived severity of "fetal injuries with the baby bore vaginally" (39.4\% vs. $90.4 \%)$ and "perineal tears" $(43.9 \%$ vs. 87.7\%). Fewer of them possess insurance for $C D$ in a private hospital $(30.9 \%$ vs. $35.6 \%)$, but there was no statistically significant difference. More of them reported that "advice from relatives/friends" (83.7\%) and "health care professionals" (82.6\%) were their cues for action.

Table 4 shows the women's perceptions of $\mathrm{CD}$ according to the five constructs of HBM, and the comparison between the two groups of women. It was revealed that women considered themselves prone to "abdominal wound infections" $(\mathrm{n}=4)$, and "a long recovery time" $(\mathrm{n}=3)$ due to $\mathrm{CD}$. Women who expressed a preference for $\mathrm{CD}$, in comparison with those who preferred $\mathrm{VB}$, were more likely to identify the benefits of $\mathrm{CD}$. The top benefits were being able to "avoid prolonged labor" (100\% vs. $75.2 \%)$, "prevent labor pain (97.2\% vs. $69.9 \%)$, "reduction of fear induced by prolonged labor and fetal injuries" (91.8\% vs. $50.7 \%$ ), and being "a faster and more convenient way of delivery" (91.8\% vs. 51.7\%). On all of these items, statistically significant differences between the two groups of women, with $\mathrm{p}<0.001$. These women, compared with their counterparts, were also less likely

Table 4 Constructs of HBM relating to women's perceptions of cesarean delivery (CD): Comparison between women who prefer a vaginal birth (VB) and a cesarean delivery (CD) $(n=319)$

\begin{tabular}{|c|c|c|c|}
\hline \multirow[t]{2}{*}{ Women's perceptions of cesarean delivery (CD) } & Prefer VB $(n=246)$ & Prefer CD $(n=73)$ & P-value \\
\hline & n (\%) & \multicolumn{2}{|l|}{$\mathrm{n}(\%)$} \\
\hline \multicolumn{4}{|l|}{ Perceived susceptibility } \\
\hline Abdominal wound infection & $4(0.02)$ & $0(0.0)$ & 0.329 \\
\hline Long recovery time & $1(0.004)$ & $2(0.03)$ & 0.140 \\
\hline \multicolumn{4}{|l|}{ Perceived benefits } \\
\hline A faster/more convenient method of delivery & $127(51.7)$ & $67(91.8)$ & $<0.001^{* * *}$ \\
\hline A trendy/modern method of delivery & $109(44.3)$ & $60(82.2)$ & $<0.001^{* * *}$ \\
\hline Less fear of prolonged labor and fetal injuries & $124(50.7)$ & $67(91.8)$ & $<0.001^{* * *}$ \\
\hline Avoid pain induced by repetitive vaginal examinations & $111(45.2)$ & $55(75.4)$ & $<0.001^{* * *}$ \\
\hline Avoid the necessity of inducing labor & $123(50.0)$ & $59(80.8)$ & $<0.001^{* * *}$ \\
\hline Prevent labor pain & $172(69.9)$ & $71(97.2)$ & $<0.001^{* * *}$ \\
\hline Avoid prolonged labor & $185(75.2)$ & $73(100)$ & $<0.001^{* * *}$ \\
\hline Preserve sexual function and genital appearance & $94(38.2)$ & $43(58.9)$ & $0.002^{* *}$ \\
\hline Minimize potential sexual dissatisfaction & $66(26.9)$ & $36(49.3)$ & $<0.001^{* * *}$ \\
\hline Allows tubal ligation after CD & $94(38.2)$ & $32(43.8)$ & 0.388 \\
\hline Allows better planning of maternity leave & $168(68.3)$ & $58(79.4)$ & 0.065 \\
\hline Allows better planning of paternity leave & $165(67.1)$ & $55(75.4)$ & 0.180 \\
\hline Avoids the uncertainty of the timing of the delivery & $185(75.2)$ & $60(82.2)$ & 0.214 \\
\hline Can select an auspicious date to deliver my baby & $162(65.9)$ & $49(67.1)$ & 0.840 \\
\hline Year, date, time, and weekday of birth affect one's fate & $70(28.4)$ & $34(46.6)$ & $0.004^{* *}$ \\
\hline \multicolumn{4}{|l|}{ Perceived severity } \\
\hline Concern over the anesthesia complications of CD & $228(92.7)$ & $45(61.6)$ & $<0.001^{* * *}$ \\
\hline Afraid of uterine scar ruptures if a cesarean delivery is performed & $125(50.9)$ & $25(34.2)$ & $0.013^{*}$ \\
\hline Afraid of adhesion formation if a cesarean delivery is performed & $137(55.7)$ & $30(41.1)$ & $0.028^{*}$ \\
\hline \multicolumn{4}{|l|}{ Perceived barriers } \\
\hline Extra cost of CD out of own pocket & $125(50.8)$ & $38(52.1)$ & 0.852 \\
\hline Cannot choose CD in a public hospital & $141(57.4)$ & $61(83.6)$ & $<0.001^{* * *}$ \\
\hline \multicolumn{4}{|l|}{ Cues to action } \\
\hline Healthcare professionals advise CD & $132(53.6)$ & $53(72.6)$ & $0.004^{* *}$ \\
\hline Relatives/friends advise CD & $40(16.2)$ & $33(45.2)$ & $<0.001^{* * *}$ \\
\hline I heard negative stories from relatives/friends about their vaginal delivery & $72(29.3)$ & $34(46.6)$ & $0.006^{* *}$ \\
\hline I have a family history of difficult births & $44(17.9)$ & $27(37.0)$ & $0.001^{* * *}$ \\
\hline
\end{tabular}


to perceive the severity of using anesthesia during $C D$ (61.6\% vs. $92.7 \%, \mathrm{P}=<0.001$ ), less worried about "uterine scar ruptures" (34.2\% vs. 50.9\%), and "the formation of scar adhesion" (41.1\% vs. $55.7 \%)$. They also were more likely to consider the restrictions placed by public hospitals on CDMR to be a barrier to the use of CD $(57.4 \%$ vs. 83.6\%). "Advice from health care professionals" (72.6\%), "friends/relatives" (45.2\%), "have heard negative stories about VB" (46.6\%), and "a family history of difficulty in childbirth" (37.0\%) were all cues to action for those who expressed a preference for CD.

\section{Comparison of mean scores between the two preference groups}

The mean scores of the constructs of the HBM were analyzed and compared between the two groups of women. As perceived susceptibility was only reported by a few women and there was no statically significant difference between the VB or CD groups, no further analysis was conducted on this construct.

A comparison of the mean scores for the remaining four domains of HBM between the two groups women is given in Table 5. The comparison of the four constructs of the perceptions of VB showed that women who preferred VB had a significantly higher mean score on perceived benefits (12.61 vs. 7.52 ) and a lower mean score on perceived severity (2.54 vs. 5.40 than those who preferred $C D(P<0.001)$.

The higher mean scores for the four constructs of the perceptions of CD indicated that women who preferred $\mathrm{CD}$ had a significantly higher mean score on perceived benefits (15.66 vs. 9.63), a lower mean score on perceived severity (1.6\% vs. 2.63$)$, and a higher mean score on cues to action (2.05 vs. 1.22) than those who preferred VB $(\mathrm{P}<0.001)$.

\section{Constructs of HBM as predictors of a maternal preference} for cesarean delivery

A logistic regression analysis was conducted to assess whether maternal characteristics and the constructs of HBM were predictive of a maternal preference for CD (Table 5). Variables that had been found in a previous analysis to be statistically significant, including the demographic characteristics of the respondents as well as the HBM constructs, were entered as independent variables for analysis. The preference for $\mathrm{CD}$ as the mode of birth was set to be the dependent variable.

As shown in Table 5, a statistically significant link to a maternal preference for $\mathrm{CD}$ was found for those who perceived that $C D$ offered higher benefits $(O R=1.565, P$ $=0.0001)$ and less severity $(\mathrm{OR}=0.677, \mathrm{P} 0.026)$, and that $\mathrm{VB}$ offered less benefits $(\mathrm{OR}=0.712, \mathrm{P}<0.0001)$ and more severity $(\mathrm{OR}=1.127, \mathrm{P}=0.011)$.

\section{Discussion}

The age-specific fertility statistics reported by the Hong Kong Census and Statistics Department in 2013 [6] show that the majority of births occur among women in the age group of 25-34. In this study, the majority of women of childbearing age were between 26-35 years of age, showing that the sample in this study is comparable to that for Hong Kong in general. In addition, the largest proportion of the sample were living in the New Territories (52\%), followed by Kowloon (39.2\%) and Hong Kong Island (8.8\%). These percentages are consistent with the geographical distribution of the Hong Kong female population, with the majority of women $(51.9 \%)$

Table 5 The constructs of HBM between the two groups of women who prefer a vaginal birth (VB) or a cesarean delivery (CD)

\begin{tabular}{|c|c|c|c|}
\hline \multicolumn{4}{|l|}{$\overline{M e a n} \pm$ SD } \\
\hline & Prefer VB $(n=246)$ & Prefer CD $(n=73)$ & $P$ value \\
\hline Perceived benefits (VB) & $12.61 \pm 3.577$ & $7.53 \pm 4.285$ & $<0.001^{* * *}$ \\
\hline Perceived severity (VB) & $2.45 \pm 2.334$ & $5.40 \pm 2.419$ & $<0.001 * * *$ \\
\hline Perceived barriers (VB) & $0.35 \pm 0.548$ & $0.45 \pm 0.668$ & 0.167 \\
\hline Cues to action (VB) & $1.50 \pm 0.951$ & $1.33 \pm 1.131$ & 0.208 \\
\hline Perceived benefits (CD) & $9.63 \pm 6.035$ & $15.66 \pm 5.697$ & $<0.001^{* * *}$ \\
\hline Perceived severity (CD) & $2.63 \pm 1.548$ & $1.60 \pm 1.431$ & $<0.001 * * *$ \\
\hline Perceived barriers (CD) & $2.08 \pm 1.572$ & $2.36 \pm 1.513$ & 0.180 \\
\hline Cues to action (CD) & $1.22 \pm 1.241$ & $2.05 \pm 1.373$ & $<0.001^{* * *}$ \\
\hline \multicolumn{2}{|c|}{ Logistic regression (Forward Wald): Predictive constructs for preferring CD } & Odd Ratio $(95 \% \mathrm{Cl})$. & P-value \\
\hline \multicolumn{2}{|l|}{ Perceived benefits (CD) } & $1.127(1.028-1.235)$ & $0.011^{*}$ \\
\hline \multicolumn{2}{|l|}{ Perceived benefits (CD) } & $0.677(0.480-0.955)$ & $0.026^{*}$ \\
\hline \multicolumn{2}{|l|}{ Perceived benefits (VB) } & $0.712(0.625-0.810)$ & $<0.0001 *$ \\
\hline \multicolumn{2}{|l|}{ Perceived severity (VB) } & $1.565(1.264-1.938)$ & $<0.0001 *$ \\
\hline
\end{tabular}


living in the New Territories in 2011 [6]. It is concluded that the sample in this study is representative of women of childbearing age in Hong Kong.

In this study, the majority of the Hong Kong women indicated their preference for VD (77.1\%) over CD (22.9\%). This percentage is similar to that found in other countries of Asia, with a high percentage of women in South Korea (96.9\%), Singapore (95.1\%), and Turkey (84.1\%), preferring VB as their mode of birth [5, 7, 27]. A high preference for $\mathrm{VB}$, at $89 \%$, was also reported in a study conducted in North Carolina, USA [44]. The reported $22.9 \%$ preference rate for $\mathrm{CD}$ is lower than in the urban regions of China (54.1\%) [54], Taiwan (35.2\%) [8]. However, at $22.9 \%$ the preference rate for CDs expressed by the women in this study is somewhat higher than the rate for elective $\mathrm{CDs}$ for non-medical indications in Hong Kong in 2004, at 16.7\% [19]. That percentage also exceeds the rate of $10-15 \%$ for CDs considered optimal by the World Health Organization [53]. This indicates that an increasing number of Hong Kong women prefer to give birth by $\mathrm{CD}$.

This study found that the majority of women (61.4\%) received information on mode of birth from their obstetrician. However, it has been revealed that most of the information given out by obstetricians relates to the birth procedure rather than to the possible risks and benefits of the different modes of delivery [13]. This study also found that women identified nurses (22.3\%) as less likely to have been a source of information related to birth than their own relatives $(32.9 \%)$ and friends (27\%). This result shows that obstetricians and nurses are not providing sufficient information. More education on health concerns and modes of birth is needed if childbearing women are to make an informed decision on mode of birth.

\section{Characteristics of women preferring two different modes of delivery}

The results of this study indicate that age, level of education, and occupation are significant correlates for women's preference on mode of birth. A preference for CD was associated with advanced maternal age. Previous studies have speculated about the relationship between advanced maternal age and the likelihood of $\mathrm{CD}$, in that pregnant women of advanced age have been shown to hold a strong belief that their advanced age puts them and their baby at risk during labor and delivery, due to the physiological factors related to aging [53]. A study in Taiwan also revealed that older women worried whether their baby would be able to pass safely through the vaginal canal [5]. This concern has led to the belief that CD is safer mode of delivery for pregnant women of advanced age.

Women with higher levels of education were found to be more likely to choose VB as their preferred mode of birth. This finding is inconsistent with other reports indicating that more educated women would choose CD as the mode of delivery [56]. Further studies are required to determine the reasons for this difference, such as the level of knowledge on childbirth held of these women, or social and economic differences between the studied populations.

The women in this study who were health professionals were more likely to choose a vaginal birth. This is consistent with other studies that showed that the majority of obstetricians and nurses preferred to have a VB due to their consideration that VB is a normal and natural low-risk life event, and to their better understanding of the complications of $\mathrm{CD}[2,26,50]$.

\section{Considerations when making decisions on mode of delivery}

The most common concerns of women who preferred VB were over maternal health (73.2\%) and the health of the baby $(85 \%)$. This is consistent with the results from other studies. Studies have reported that the majority of women considered VB to be a safer mode of birth for the mother (81.7\%) and the neonate (72.8\%) [42]. The majority of women prefer VB because it allows for an earlier discharge from hospital and for the mother to recover more quickly [5]. The risk of surgery and anesthetic drugs passing to the neonate in $\mathrm{CD}$ is also a consideration for women who prefer VB [10].

On the other hand, the most common reasons for women to request a $\mathrm{CD}$ was to avoid labor pain (79.5\%), concern for the health of the newborn (53.4\%), and worry about potential birth trauma (32.9\%) and respiratory trauma (33.7\%) to the newborn from a vaginal birth. Labor is often thought of as one of the more painful events in human experience and women are fearful of experiencing pain during labor [7].

As a vaginal birth is regarded as "the most natural process of birth," women who want to have a natural birth prefer VB (49, 6\%). This is also an important reason given by the nearly $90 \%$ of women in other studies who choose VB [10, 27]. However, women who preferred $\mathrm{CD}$ expressed a wish for certainty about the date of the birth (27.4\%), and thus to be better able to plan for maternity leave (27.4\%). This is perhaps understandable for contemporary women who have their own career, with $19.2 \%$ of the participants indicating that they wanted to have the right to choose the mode by which their baby would be delivered.

\section{The HBM constructs and maternal preference on mode of birth}

There were significant differences between women who preferred VB and CD in their perceptions of the benefits and severity of different modes of birth. Women who preferred $\mathrm{VB}$ perceived the benefits of $\mathrm{VB}$ as being that 
it is a normal and natural process $(100 \%)$, recovery is faster after delivery, it allows for earlier breastfeeding, and no unnecessary surgery and anesthesia is involved in the process. These women were also less worried about fetal injuries during vaginal birth than those who preferred CD. Women who preferred CD believed that by opting for this process they would be able to avoid prolonged labor (100\%), labor pain (97.2\%), and fetal injuries, as well as have a fast and convenient delivery. For women who preferred $\mathrm{CD}$, advice from health professionals, negative stories of $\mathrm{VB}$ from relatives and friends, as well as a family history of difficult births were the cues for action.

Women who preferred VB had a significantly higher mean score on the perceived benefits and a lower score on the perceived severity of VB than those who preferred CD. Women who preferred CD had a significantly higher mean score on the perceived benefits and a lower score on the perceived severity of $\mathrm{CD}$, and a higher mean score on cues to action than those who preferred VB. These results are consistent with those of other studies. Studies have confirmed that perceived benefits are a predictive factor of delivery preference [14, 34, 35]. Women weighed the considerations of the maternal/fetal benefits and complications of a particular mode of birth [10, 45], demonstrating the importance of these constructs of HBM in decision making.

Cues to action indicated that advice from professionals played an important role in the maternal decision on mode of birth, especially for $\mathrm{CD}$. It has been reported that advice from physicians is an important influence on women in their choice of mode of birth [16]. A study has shown that only $5 \%$ of women continued to attempt a VB when they perceived that their obstetrician held an unfavorable attitude towards VB [15]. Some midwives have actually been reported to encourage women to undergo a $C D$ in order to protect their pelvic floor and reduce the risks of developing urinary or fecal incontinence [36].

The logistic regression analysis of the HBM demonstrated that the constructs of perceived benefits, perceived severity, and cues to action were significant correlates of the maternal preference on mode of birth. These factors should be considered when designing educational interventions to help women make the decision on the mode of delivery that is most appropriate for their needs.

\section{Limitations}

This study is not without limitations. First, the participants of this study were women recruited outside public hospitals, or Maternal and Child Health Centers. Those who visited private hospitals were not recruited, which could lead to bias in sample recruitment. Second, this study explored only the perception of women towards the two types of modes of delivery but not the actual delivery mode they had or will be taken. Third, this was a cross-sectional study, and thus there is limited information on how women form a preference for mode of delivery, perception changes, and the dynamic decision making process throughout pregnancy in their preference for mode of delivery.

\section{Conclusions}

The results of this study provide a better understanding of the prevalence and the factors influencing the choice of mode of delivery among childbearing women in Hong Kong. However, a longitudinal study is needed to identify if women change their perception and choice on mode of delivery during pregnancy or after delivery.

Although more women in this study preferred VB, there is evidence of a growing preference for $\mathrm{CD}$. While age, level of education, and involvement in a healthrelated profession influenced the decision made by the women in this study, the perceptions of the benefits and severity of the different modes of delivery were the most important considerations. There is also evidence that advice from health professionals plays an important role in the maternal decision on mode of birth. There is a need for comprehensive information on the benefits and severity of the different modes of delivery, instead of just the birth procedures. Women of childbearing age should have a right to receive comprehensive and unbiased information from health professionals so that they can make an informed choice on the mode of birth that is most suitable for them.

\section{Competing interests}

The authors declare that there is no competing interest in this project.

\section{Authors' contributions}

All authors were involved in the conception of the study and design, AYL and SFL developed the questionnaire for data collection, and SFL collected data. Both AYL and SFL analysis and interpretation of data, SFL and LD drafted the article. Both LD and AYL critically revised the manuscript for important intellectual content, and $A Y L$ approved the final version to be submitted.

\section{Acknowledgments}

The authors would like to thank the following final year BSN students' contribution in data collection, data entry and preliminary data analysis: Cheng PH, Choi NC, Hui SS, Lam NC, Fung YM, Lam TC, Wong C, Wong TH, \& Poon CY. This project received no funding.

Received: 17 July 2014 Accepted: 26 June 2015

Published online: 20 July 2015

\section{References}

1. Altman D, Ekström A, Forsgren C, Nordenstam J, Zetterström J. Symptoms of anal and urinary incontinence following cesarean section or spontaneous vaginal delivery. Am J Obstet Gynecol. 2007;197(5):512.e1-7.

2. Backe B, Salvesen KA, Sviggum O. Norwegian obstetricians prefer vaginal route of delivery. Lancet. 2002;359(9306):629.

3. Barber EL, Lundsberg LS, Belanger K, Pettker CM, Funai EF, Illuzzi JL. Indications contributing to the increasing cesarean delivery rate. Obstet Gynecol. 2011;118(1):29-38. doi:10.1097/AOG.0b013e31821e5f65. 
4. Boer K, England K, Godfried MH, Thorne C. Mode of delivery in HIV-infected pregnant women and prevention of mother-to-child transmission: Changing practices in Western Europe. HIV Medicine. 2010;11(6):368-78.

5. Buyukbayrak EE, Kaymaz OO, Kars BB, Karsidag AK, Bektas EE, Unal OO, et al. Caesarean delivery or vaginal birth: Preference of Turkish pregnant women and influencing factors. J Obstet Gynaecol. 2010;30(2):155-8.

6. Census and Statistics Department. Women and men in Hong Kong key statistics 2013. Retrieved December 3, 2013 from http:// www.statistics.gov.hk/pub/B11303032013AN13B0100.pdf

7. Chong EY, Mongelli MM. Attitudes of Singapore women toward cesarean and vaginal deliveries. Int J Gynecol Obstet. 2003;80(2):189.

8. Chu KH, Tai CJ, Hsu CS, Yeh MC, Chien LY. Women's preference for cesarean delivery and differences between Taiwanese women undergoing different modes of delivery. BMC Health Services Research. 2010;10(1):138.

9. Davidson MR, London ML, Ladewig PW. Olds' maternal newborn nursing \& women's health across the lifespan (9th ed). Upper Saddle River, N.J.: Pearson Education, Inc.; 2012.

10. Dursun P, Yanik F, Zeyneloglu H, Baser E, Kuscu E, Ayhan A. Why women request Cesarean section without medical indication? J Matern Fetal Neonatal Med. 2010;24(9):1133-7.

11. Eden KB, Hashma JN, Osterweil P, Nygren P, Guise J. Childbirth preferences after Cesarean birth: A review of the evidence. Birth: Issues In Perinatal Care. 2004;31(1):49-60

12. Einarsdóttir K, Kemp A, Haggar FA, Moorin RE, Gunnell AS, Preen DB, et al. Increase in caesarean deliveries after the Australian private health insurance incentive policy reforms. Plos ONE. 2012;7(7):1-5.

13. Emmett $\mathrm{CL}$, Shaw $\mathrm{AR}$, Montgomery AA. Women's experience of decision making about mode of delivery after a previous caesarean section: The role of health professionals and information about health risks. BJOG. 2006;113:1438-45.

14. Fardi Azar Z, JafariShabiri M. A survey for determining factors on women's attitudes toward vaginal and cesarean delivery. J Tabriz University Med Sci. 2003;37(59):66-9.

15. Fraser M, Maunsell E, Hodnett E, Moutquin JM. Randomized controlled trial of a prenatal vaginal birth after cesarean section education and support program. Am J Obsteavbt Gynecol. 1997;176(2):419-25.

16. Gamble J, Creedy D. Women's request for a cesarean section: a critique of the literature. Birth: Issues In Perinatal Care. 2002;27(4):256-63.

17. Hatcher LA, A Step-by-Step Approach to using the SAS ${ }^{\oplus}$ System for factor Analysis and Structural Equation Modeling. Cary, NC: SAS Institute Inc. 1994; p73.

18. Hong Kong Baptist Hospital. Service Charges. Retrieved April 21, 2013 from http://www.hkbh.org.hk/chi/service_charge.php

19. Hong Kong College of Obstetricians and Gynaecologists. Hong Kong Obstetrics and Gynaecology Territory-Wide Audit Report. 2004, Hong Kong: Author.

20. Hong Kong Sanatorium \& Hospital. Maternity Charges. Retrived June 30, 2015 from http://www.geobaby.com/forum/thread93527.html

21. Hsu K, Liao P, Hwang C. Factors affecting Taiwanese women's choice of Cesarean section. Soc Sci Med. 2008;66(1):201-9.

22. Information Services Department. Hong Kong: The facts. Retrieved April 21, 2013 from Hong Kong Special Administrative Region Government, Web site: http://www.gov.hk/en/about/abouthk/factsheets/docs/population.pdf

23. Janz NK, Becker MH. The health belief model: A decade later. Health Quarterly. 1984;11(1):1-47.

24. Jun Z, Yinghui L, Meikle S, Junchi Z, Wenyu S, Zhu L. Cesarean delivery on maternal request in Southeast China. Obstet Gynecol. 2008;111(5):1077-82.

25. Kerr-Wilson R. Caesarean section on demand. Curr Obstet Gynaecol. 2001;11(2):126-8.

26. Lataifeh I, Zayed F, Al-kuran O. Jordanian obstetricians' personal preference regarding mode of delivery. Acta Obstetricia et Gynecologica. 2009;88:733-6.

27. Lee $S$, Khang $Y$, Lee M. Women's attitudes toward mode of delivery in South Korea-a society with high Cesarean section rates. Birth: Issues In Perinatal Care. 2004;31(2):108-16.

28. Lumbiganon P, Laopaiboon M, Gülmezoglu AM, Souza JP, Taneepanichsku $S$, Ruyan $\mathrm{P}$, et al. Method of delivery and pregnancy outcomes in Asia: The WHO global survey on maternal and perinatal health 2007-08. Lancet. 2010;375(9713):490-9.

29. Lydon-Rochelle MT, Gardella C, Cárdenas V, Easterling TR. Repeat Cesarean delivery: What Indications are recorded in the medical chart? Birth: Issues In Perinatal Care. 2006;33(1):4-11.

30. MacMillan DT. Understanding the health beliefs of first time mothers who request an elective cesarean versus mothers who request a vaginal delivery. Nursing Dissertations. 2010;14:23-33.
31. Martin JA, Hamilton BE, Ventura SJ, Osterman MJK, Wilson EC, Mathews TJ. Births: Final Data for 2010. National Vital Statistics Reports. 2012;61:1.

32. McGrath P, Ray-Barruel G. The easy option? Australian findings on mothers' perception of elective Caesarean as a birth choice after a prior Caesarean section. Int J Nurs Pract. 2009;15(4):271-9.

33. Melender $\mathrm{HL}$. Fears and coping strategies associated with pregnancy and childbirth in Finland. J Midwifery Womens Health. 2002;47:256-63.

34. Mohammadpourasl A, Asgharian P, Rostami F, Azizi A, Akbari H. Investigating the choice of delivery method type and its related factors in pregnant women in Maragheh. Journal of Knowledge and Health. 2009:4(1):36-9.

35. Mohtasham G, Atefeh A. Application of Health Belief Model for predicting delivery method among pregnant women of Semirom: A Cross-sectional research. World Applied Sciences Journal. 2013;22(4):494-9.

36. Monari F, Di Mario S, Facchinetti F, Basevi V. Obstetricians' and Midwives' Attitudes toward Cesarean Section. Birth: Issues In Perinatal Care. 2008;35(2):129-35.

37. Murray S. Relation between private health insurance and high rates of Caesarean section in Chile: Qualitative and quantitative study. BMJ. 2000;321(7275):1501-5.

38. National Institutes of Health. State-of-the-Science conference statement. Cesarean delivery on maternal request. Obstet Gynecol. 2006;107:1386-97.

39. Pallasmaa N, Ekblad U, Aitokallio-Tallberg A, Uotila J, Raudaskoski T, Ulander $\checkmark$, et al. Cesarean delivery in Finland: Maternal complications and obstetric risk factors. Acta Obstetricia et Gynecologica Scandinavica. 2010;89(7):896-902.

40. Pang $\mathrm{M}$, Leung $\mathrm{T}$, Lau $\mathrm{T}$, Chung $\mathrm{KH}$. Impact of first childbirth on changes in women's preference for mode of delivery: follow-up of a longitudinal observational study. Birth: Issues In Perinatal Care. 2008;35(2):121-8.

41. Penna L, Arulkumaran S. Cesarean section for non-medical reasons. Int J Gynaecol Obstet. 2003;82(3):399-409.

42. Pevzner L, Preslicka C, Bush MC, Chan K. Women's attitudes regarding mode of delivery and Cesarean delivery on maternal request. J Matern Fetal Neonatal Med. 2001;24(7):894-9.

43. Robson S, Carey A, Mishra R, Dear K. Elective caesarean delivery at maternal request: A preliminary study of motivations influencing women's decision-making. Aust N Z J Obstet Gynaecol. 2008;48(4):415-20.

44. Romero ST, Coulson CC, Galvin SL. Cesarean delivery on maternal request: A western North Carolina perspective. Matern Child Health J. 2012;16(3):725-34.

45. Schindl M, Bimer $P$, Reingrabner M, Joura $E$, Husslein $P$, Langer M. Elective cesarean section vs. spontaneous delivery: a comparative study of birth experience. Acta Obstetricia et Gynecologica Scandinavica. 2003;82(9):830-40,

46. Serçekuş $P$, Okumuş $H$. Fears associated with childbirth among nulliparous women in Turkey. Midwifery. 2009;25(2):155-62.

47. Simpson K, Thorman K. Obstetric "Convenience": Elective induction of Labor, Cesarean Birth on Demand, and Other Potentially Unnecessary Interventions. J Perinat Neonatal Nurs. 2005;19(2):134-44.

48. Stanton C, Ronsmans C. Recommendations for routine reporting on indications for Cesarean delivery in developing countries. Birth: Issues In Perinatal Care. 2008:35(3):204-11.

49. Stjernholm $Y$, Petersson K, Eneroth E. Changed indications for Cesarean sections. Acta Obstetricia Et Gynecologica Scandinavica. 2010;89(1):49-53.

50. Wax JR, Cartin A, Pinette MG. Patient Choice Cesarean-The Maine Experience. Birth: Issues In Perinatal Care. 2005;32(3):203-6.

51. Weaver JJ, Statham H, Richards M. Are There "Unnecessary" Cesarean Sections? Perceptions of Women and Obstetricians About Cesarean Sections for Nonclinical Indications. Birth. 2007;2007(34):32-41. doi:10.1111/j.1523-536X.2006.00144.X.

52. Wiklund I, Edman G, Andolf E. Cesarean section on maternal request: Reasons for the request, self-estimated health, expectations, experience of birth and signs of depression among first-time mothers. Acta Obstetricia Et Gynecologica Scandinavica. 2007;86(4):451-6.

53. World Health Organization. Appropriate technology for birth. Lancet. 1985:2:436-7.

54. Xing LF, Ling $X$, Yan $G$, Ronsmans $C$. Factors influencing rising caesarean section rates in China between 1988 and 2008. Bulletin Of The World Health Organization. 2012;90(1):30-39A.

55. Yip P, Lee J, Cheung Y. The influence of the Chinese zodiac on fertility in Hong Kong SAR. Soc Sci Med. 2002;55(22):1803-12.

56. Zhang JL, Meikle S, Zheng J. Cesarean delivery on maternal request in Southeast China. Obstet Gynecol. 2008;111:1077-82.

57. Zwelling E. The emergence of high-tech birthing. J Obstet Gynecol Neonatal Nurs. 2008;37(1):85-93. 